\title{
Myouclear Breakdown in Sporadic Inclusion Body Myositis
}

\author{
Satoshi Nakano ${ }^{1,2}$ and Hirofumi Kusaka² \\ ${ }^{1}$ Osaka City general Hospital \\ ${ }^{2}$ Kansai Medical University \\ Japan
}

\section{Introduction}

Sporadic inclusion body myositis (s-IBM) is categorized as a form of the idiopathic autoimmune inflammatory myopathies and it is common myopathy in the elderly. Unlike polymyositis which preferentially shows proximally-dominant skeletal muscle involvement, s-IBM displays a unique distribution of muscle atrophy and weakness: patients with s-IBM often have severely atrophic muscles in the forearm flexors and quadriceps femoris. Unlike other inflammatory myopathies, this disorder is usually unresponsive to therapy and has a slowly progressive course. The pathological findings define the diagnosis of s-IBM. They include: 1) mononuclear cell infiltration surrounding and invading non-necrotic muscle fibers; 2) Congo-red positive inclusions; and 3) vacuoles lined by basophilic materials called rimmed vacuoles. The pathogenesis of s-IBM remains undetermined.

In s-IBM muscle biopsy, electron microscopy shows myonuclear abnormalities, such as filamentous inclusions and rare nuclear envelope breakdown. Based on such observation, it has been proposed that the myonuclear change is closely associated with the pathogenesis. Also, several studies have indicated that a focal cytoplasmic deposits of nucleus-proper and nucleus-oriented proteins in s-IBM abnormal muscle fibers. Recently, elemental components of the nucleus, such as nuclear envelope proteins (e.g., emerin and lamin A/C), histone H1, or DNA have been detected on vacuolar membranes or within vacuoles. The results strongly support the theory that myonuclear breakdown results in rimmed vacuoles.

In this chapter, we first present figures that show abnormal localization of nuclear proteins associated with MAP kinase in s-IBM muscle fibers. The results suggest that inhibition of nuclear transport during myogenesis. We next describe abnormal localization of histone H1 in s-IBM with some comments on a unique character of histone $\mathrm{H} 1$ among several histones as a transcriptional regulator and a player in the DNA damage response. Lastly, our recent investigation of DNA damage is included. Our studies in s-IBM support the theory that nuclear damage is closely associated with its etiology.

\section{Background}

\subsection{History}

The term "inclusion body myositis (IBM)" was proposed in 1971. As some of the patients who had been diagnosed as having IBM in earlier studies were young, and the pathology showed no inflammation (Yunis and Samaha 1971), the diagnosis of these patients could 
be "hereditary inclusion body myopathy (h-IBM)" or "myofibrillar myopathy" according to the current definition. Sporadic inclusion body myositis (s-IBM) is now considered as a form of idiopathic inflammatory myopathies which include polymyositis and dermatomyositis (Dalakas 2006, Needham and Mastaglia 2008). The diagnosis of s-IBM was initially done based on the presence of unique tubulofilamentous inclusions in the nucleus and cytoplasm under electron microscopic study in patients who had been usually diagnosed as having chronic polymyositis. Later, it became recognized as a common form of inflammatory myopathy in the elderly, which shows slowly progressive, frequent involvement of distal muscles, male predominance, and resistance of corticosteroid therapy (Lotz et al 1989). The characteristic histopathological findings are nuclear and cytoplasmic tubulofilamentous inclusions and vacuoles lined by basophilic materials (rimmed vacuoles) (Carpenter et al 1978). In 1991, Mendel et al. identified Congo-red positive inclusions in s-IBM muscle fibers, which subsequently were shown to be composed of $\beta$-amyloid (Askanas et al 1992). In 1995, the diagnostic criteria for s-IBM were proposed (Griggs et al 1995). According to it, the pathological diagnosis of s-IBM necessitates 1) mononuclear cell infiltration surrounding and invading non-necrotic muscle fibers; 2) Congo-red positive inclusions in light microscope or tubulofilaments of about $15-18 \mathrm{~nm}$ in diameter in electron microscopic study; and 3) rimmed vacuoles. Each of these findings alone is not specific to s-IBM. Collection of inflammatory cells surrounding and invading non-necrotic muscle fibers is found in polymyositis. Detection of congophilic inclusions is one of the hallmarks of myofibrillar myopathy (Selcen and Engel 2010). In distal myopathy with rimmed vacuoles (DMRV)/hereditary inclusion body myopathy (h-IBM), the presence of rimmed vacuoles is diagnostic, but the muscle tissue shows no inflammatory exudates (Nonaka et al 1998). The definite diagnosis of s-IBM needs all of the three findings.

The muscle biopsy studies have provided important information about the pathological mechanism of each change in s-IBM. By analyzing subtypes of cells infiltrating to muscle tissue or immunological molecular ligand-receptor relationships have indicated almost identical immunological mechanism of s-IBM to that of polymyositis. In s-IBM and polymyositis, cytotoxic CD8-positive T-cells invade MHC-I-expressing muscle fibers (Dalakas 2006). In both, myeloid dendritic cells were frequently surrounded and sometimes invading non-necrotic fibers. The radiation of myeloid dendritic cells in dense collections of inflammatory exudates containing $\mathrm{T}$ cells suggests local intramuscular antigen presentation in s-IBM and polymyositis (Greenberg et al 2007a).

Concerning to congophilic inclusions, they are generally thought to be composed of $\beta$ amyloid and its related proteins as detected in the brain of neurodegenerative diseases (Askanas and Engel 2008), although their exact nature remains to be determined (Greenberg 2009). Congophilic inclusions are more conspicuous in myofibrillar myopathy than s-IBM. However, the congo-red positive inclusions in myofibrillar myopathy may not correspond to amyloid fibrils, but Z-line derived, degenerating products of myofibrils based on ultrastructural studies (Selcen and Engel 2010).

\subsection{Our study of phosphorylated proteins and nuclear components in s-IBM}

We first examined phosphorylation systems and found cytoplasmic and perinuclear deposition of nucleus-oriented and nucleus-proper proteins in s-IBM muscle fibers. The results suggest that inhibited nuclear transport of some enzymes involved in myogenesis.

As for rimmed vacuoles, some studies have shown that they are positive for autophagic/lysosome markers, suggesting that rimmed vacuoles are autophagic vacuoles 
(Kumamoto et al 2004). But autophagic vacuoles in muscle, such as those found in acid maltase deficiency are not rimmed (Dubowitz and Sewry 2007).
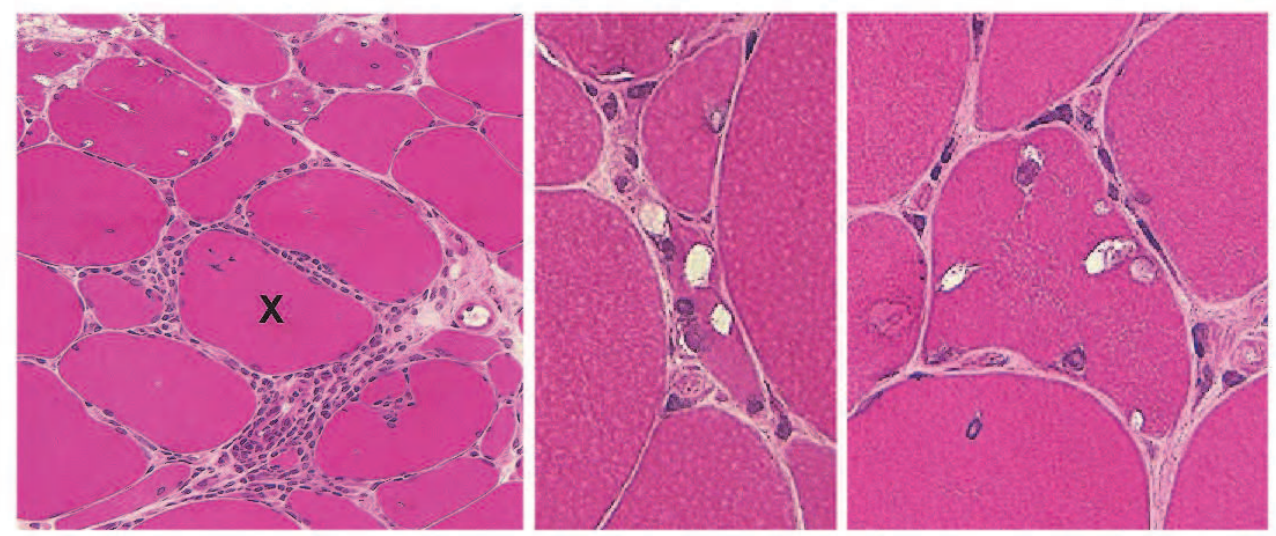

Fig. 1. H\&E stained cryostat sections of muscle biopsy in a patient with s-IBM. Mononuclear cells surround a non-necrotic fiber $(\mathrm{X})$. Vacuoles with thin blue membranes are seen. Some vacuoles contain fluffy inclusions.

The peripheries of rimmed vacuoles are often lined by basophilic materials in Hematoxyline and Eosin (H\&E) staining (figure 1). Several studies have suggested that rimmed vacuoles are product of nuclear breakdown. If vacuoles are nuclear origin, the basophilic substances should be some nuclear components. As histones represent basophilic nuclear proteins, we examined histones in s-IBM by immunnohistochemistry. The study has shown that some of the basophilic materials are indeed positive for histone $\mathrm{H} 1$, supporting nuclear breakdown in s-IBM (Nakano et al 2008).

\section{The detection of phosphorylated proteins in S-IBM}

\subsection{Phosphorylated neurofilament protein epitopes in s-IBM}

Some investigators consider that the ectopic deposition of proteins of neurodegenerative diseases is the central event in the pathogenesis of s-IBM (Askanas and Engel 2008). Others have tried to connect the inflammation and the amyloid deposition, suggesting that ectopic proteins may be induced by inflammatory cytokines (Schmidt et al 2008), which in turn provokes autophagy/lysosomal system (Lunemann et al 2007). There is, however, controversy against the real identity of the congophilic inclusions (Greenberg 2009). Some studies showed the rarity or absent reactivity for $\beta$-amyloid in patients with otherwise clinically and pathologically typical s-IBM (Sherriff et al 1995, Nalbantoglu et al 1994). The results may raise doubts over the significance of the neurodegenerative protein deposition in the pathogenesis of s-IBM. One of the authors (S Nakano), as a muscle pathologist, also found only small amounts of $\beta$-amyloid positive inclusions in s-IBM. Nonetheless, we often detected SMI-31 positive inclusions in a significant proportion of s-IBM vacuolated fibers. The antibody named SMI-31 was originally made as an antibody for the lysine-serineproline (KSP) repeats of the neurofilament proteins in which the serine is phosphorylated, and it can also attach to other proteins, such as microtubule associated protein 2, containing 
the same epitope (Nukina et al 1987). As SMI-31antibody cross-reacts with tau, it was suggested that the antibody SMI-31 could combine with tau and that tubulofilaments in sIBM might paired-helical filaments as found in the brain with Altzheimer's disease (Askanas et al 1994), although several other antibodies for tau failed to localize the inclusions (Mirabella et al 1996). We also found the gap between the results with SMI-31 and some antibodies against phosphorylated tau. It suggested existence of some other proteins containing KSP (in which S is phosphorylated) sequence.

Moreover, using several antibodies against tau, western blot studies indicated that an electrophorectic profile of a doublet within the range of 60-62 kDa isoforms, which was different from tauopathies of the central nervous system (Maurage et al 2004) and SMI-31 did not react tau in the first place, but some other nuclear proteins (Salajegheh et al 2009b).

\subsection{Phosphorylation is a dynamic process significantly involved in signal transduction}

Phosphorylation is a post-translational modification of a protein. A phosphate molecule is added to a serine or threonine residue by serine/threonine kinases and removed by specific phosphatases. The phosphorylation modification is dynamic processes and they play central roles in controlling protein function and thereby intracellular signal transduction (Hunter and Karin 1992). Phosphorylation of a tyrosine residue is another post-translational protein modification that also has significant roles in the signal transduction. As we hypothesized that the SMI-31-positive inclusions in s-IBM could indicate perturbation of the signal transduction system, we initially examined s-IBM muscle biopsy materials using antibody against phosphorylated tyrosine. Figure 2 indicates the results displaying inclusions of substances containing phosphorylated tyrosine. Western blotting studies using muscle homogenates disclosed several positive bands, one of which corresponds to ERK2, a protein kinase belonging to the MAP kinases (Nakano et al 1998). The results led us to study MAP kinase cascades.

\section{Studies of mitogen-activated protein kinase (MAPK) cascades in s-IBM}

\subsection{MAPK cascades}

The enzymes belonging to MAPK family play pivotal roles in intracellular signal transduction that transduces extracellular signals to the nucleus (Hill and Treisman 1995, Robinson and Cobb 1997). Growth factors, hormones and cytokines induce an intracellular signaling cascade that leads to the activation of MAPK kinases 1 and 2 (MKK1/2), which successively phosphorylate and activate ERK1 and ERK2. In a similar fashion, stresses and pro-inflammatory cytokines provoke signal transduction cascades, activating other MKKs. These MKKs then phosphorylate and activate p38 MAPK and cJun N-terminal kinase (JNK) (Figure 3) (Reffas and Schlegel 2000). The complex phosphorylation systems provide for a delicately tuned, prompt regulation of signals at each level of the cascade, with cross-talks with other intracellular transduction systems. Finally, activated MAPKs phosphorylate several cytoplasmic proteins associated with signal transduction, migrating into the nucleus, within which MAPKs phosphorylate and regulate transcription factors. Activated MAPKs are dephosphorylated and inactivated by phosphatases, such as MAP kinase phosphatases (MKPs) that are specialized for the deactivation of MAPKs (Keyse 2000). 
(1)

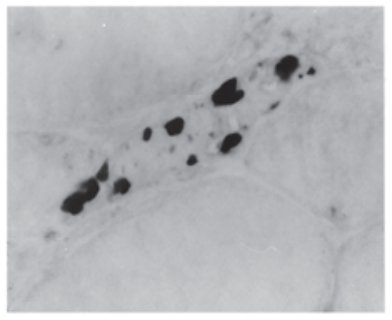

(2)

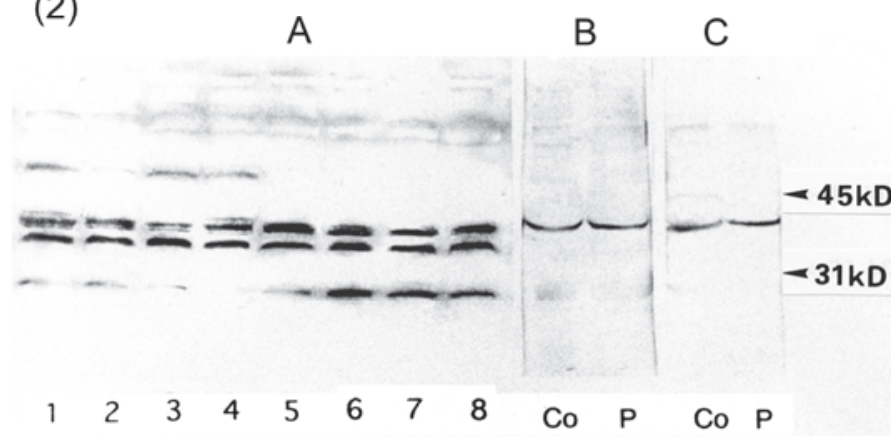

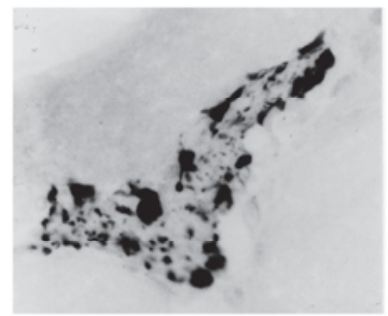

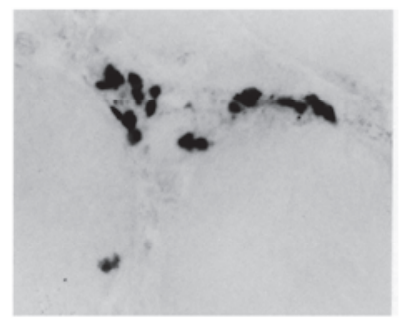

(3)

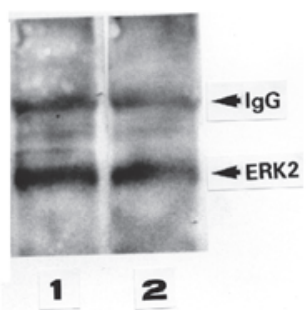

Fig. 2. Phophotyrosine study in s-IBM. (1) Localization of phosphotyrosine-containing proteins in s-IBM using anti-phosphotyrosine antibody showing positive deposits in vacuolated fibers. (2) Resolution of phosphotyrosine-containing proteins on immunoblots of muscle homogenates separated by SDS-PAGE. (A) Lanes 1-4: normal controls; 5-8: s-IBM.

(B) Immunoblots with anti-ERK2 antibody. Co-migration of about $40 \mathrm{kD}$ protein in A with ERK2. (C) Immunoblots with anti active form of ERK1/2. Co: a control; P: an s-IBM patient. Apart from $40 \mathrm{kD}$ bands, bands of $38 \mathrm{kD}$ in all cases, $27 \mathrm{kD}$ in s-IBM are present. (3) Immunoprecipitation with anti-phosphotyrosine antibody followed by immunoblotting. After separation of the immunoprecipitates on SDS-PAGE, the membrane was immunoblotted with anti-ERK2 antibody (lane 1), and anti-acitive form of ERK (lane2). Both lanes show positive bands at approximately $40 \mathrm{kD}$ of ERK2

Activated ERK1/2 phosphorylates various cytoplasmic molecules and traverse the nuclear envelope into the matrix, phosphorylating a transcription factor called Elk-1 (Figure 3) (Force and Bonventre 1998). The phosphorylated form of Elk-1 in the association with serum response factor (SRF), binds to the serum response element (SRE) of the promoter region of immediate early genes, including c-fos (Treisman, 1994). In stress-activated cascades, p38 MAPK and c-Jun N-terminal protein kinase (JNK), two subclasses of the MAPK family, take the equivalent position to ERK in the ERK cascade (Kyriakis and Avruch 1996).

\subsection{Deposits of ERK is found in s-IBM vacuolated fibers}

To start investigating the MAPK cascades, we examined ERK, p38 MAPK and JNK as well as two of their nuclear substrates by immunohistochemistry (Nakano et al 2001). The results showed that more than $60 \%$ of vacuolated fibers in s-IBM displayed very strong immunoreactive deposits of ERK that appeared round or irregular inclusions. 


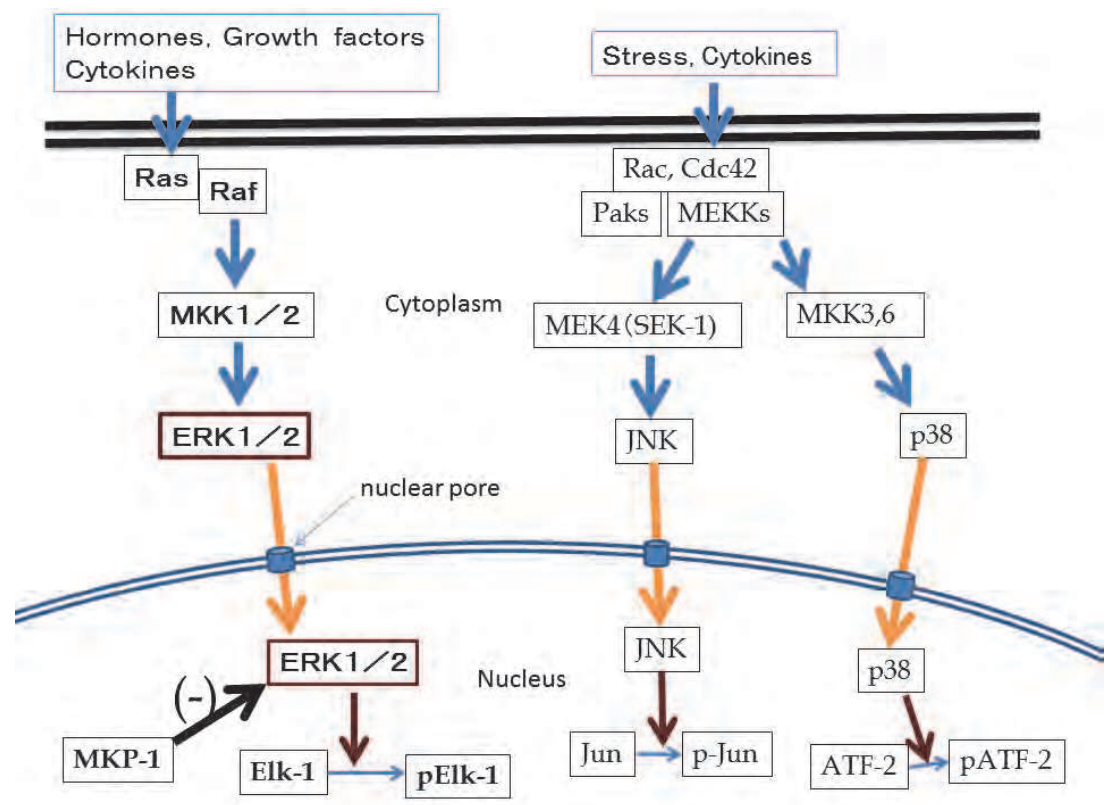

Fig. 3. MAPK cascades.

In contrast, no or few deposits positive for p38 or JNK were observed in vacuolated fibers. In control subjects, diffuse and moderate ERK, p38 and JNK immunoreactivity was found in regenerating fibers and in some degenerating fibers. As for the substrates, we immunolocalized phosphorylated Elk-1 (pElk-1) as is phosphorylated by ERK. There were strong pElk-1-immunopositive deposits in s-IBM. The localization of pElk-1 was identical with those of ERK-positive deposits, which had been confirmed in a double immunofluorescence study. The relationship between the pElk-1-positive deposits and those of SMI-31-positive deposits in vacuolated fibers in immunofluorescence study showed colocalization of pElk-1 and SMI-31-positive deposits. The substrate of JNK (c-Jun) was negative.

ERK, JNK and p38 are involved in muscle fiber maturation. In studies of muscle cell cultures, ERK, more specifically ERK2, is required in muscle fiber terminal differentiation (Li and Johnson 2006), and ERK positively regulated the activity of MyoD (a myogenic transcription factor), when the high JNK activity of myoblasts was downregulated (Gredinger et al 1998). Also, p38 may play a positive role in muscle fiber differentiation earlier than ERK via another myogenic transactivation factor, MEF2 (Zetser et al 1999, Lluís et al 2006). Regenerating fibers consist of replicating myoblasts and differentiating myotubes (Banker and Engel 2004). Thus, the increases of MAPKs in regenerating fibers in diseased muscles may correlate with the findings of the cell culture studies. Because SRF, the partner of activated Elk-1 in the nucleus, is also necessary for muscle fiber differentiation (Soulez et al 1996), ERK is probably involved in myogenesis via phosphorylation of Elk-1.

Another group has examined several MAPKs in s-IBM (Li et al 2000a). Their results also showed abnormal expression of ERK (more specifically ERK2), but not JNK or p38 in s-IBM. Moreover, immuno-histochemical analysis using antibodies against phosphoserine showed 
accumulations of phosphoserine-containing protein deposits in s-IBM vacuolated fibers. Western blots of muscle lysates demonstrated a $35 \mathrm{kD}$ phosphoprotein. They concluded that the hyperexpression of $35 \mathrm{kD}$ protein may represent cytoskeletal by-products due to ERK activation and that the abundant expression of phosphoserine-containing protein in s-IBM implies that hyperphosphorylated myofibrillar proteins may be involved in the primary disease process.

\subsection{ERK- or Elk-1-positive deposits are often perinuclear in S-IBM muscle fibers}

With nuclear DNA staining, we found that ERK- or pElk-1-positive deposits were often detected on the external surface of the nuclei, although they were sometimes present also in the cytoplasm unrelated to the nuclear localization. There were sometimes overlaps of the positive deposits and nuclei. In rare fibers, protrusions of the positive deposits into nuclei were observed. A quantitative study of the relationship between ERK-positive deposits and nuclei in ERK-positive fibers showed that $78.2 \%$ of the nuclei were closely associated with the deposits; 3.2\% of the nuclei had ERK-positive deposits occupying more than half of their area, and $75.0 \%$ of the nuclei were touched, penetrated, or partially covered by the deposits. The nuclear transcription factor pElk-1 displayed similar cytoplasmic aggregation and perinuclear localization. There was cytoplasmic and perinuclear inclusions of ERK in vacuolated fibers, but not of JNK or p38. JNK and p38, however, showed strong activity in regenerating fibers as ERK (Nakano et al 2001).

During muscle fiber differentiation, ERK is the last MAPK that becomes activated (Gredinger et al 1998, Zetser 1999). Therefore, the abnormality that causes ERK deposition may occur in the last phase of differentiation, when JNK and p38 activities have decreased.

\subsection{Analysis of MKKs and MAP kinase phosphatases}

\subsubsection{MAP kinase kinases(MKKs)}

ERK appeared to be up-regulated in vacuolated fibers in IBM and ERK is activated by MKK1/2 in the phosphorylation cascade triggered by extracellular stimuli (Fig. 3.). We therefore next tested MKK1/2 in s-IBM (Nakano et al 2003). Whereas in normal muscle fibers, weak immunoreactivity of MKK1/2 was observed, strong immunoreactivity of MKK1/2 was found in some of the regenerating or degenerating muscle fibers. In IBM, vacuolated fibers showed no or mild cytoplasmic immunoreactivity for MKK1/2, even fibers with ERK-positive inclusions. We then tested MKK3 and MKK4 to reject the possibility that other MKK might induce ERK in IBM, although MKK3 and MKK4 actually activate p38 MAPK or JNK, but not ERK (Fig. 3.) (Reffas and Schlegel 2000). Regenerating/degenerating fibers showed positive immunoreaction for these MKKs, vacuolated fibers in IBM were negative for MKK3 or MKK4.

Concerning to the increased MKKs in regenerating/degenerating fibers, growth factors promoting myogenesis (Groungs 1999) or cytokines locally produced or ischemic stresses in the affected tissue in inflammatory myopathies (Lundberg et al 1997) could induce them. As a proportion of vacuolated fibers also showed some positivity for MKK1/2, comparable myogenic factors or other extracellular signals might induce ERK cascade in vacuolated fibers in IBM. However, the intensity of the immunoreaction of MKK1/2 in vacuolated fibers was weaker than those regenerating/degenerating fibers in control specimens and the reaction did not form inclusions. The results exclude a possibility that a specific extracellular signal induces the increase of ERK protein. 


\subsubsection{MKPs}

The study of MAP kinase phosphatases (MKPs), i.e., enzymes that deactivate MAPKs, was done with MKP-1, MKP-2 and MKP-3 (Nakano et al 2003). In MKP-1 analysis, some regenerating/degenerating fibers showed strong nuclear staining with moderate cytoplasmic positivity of MKP-1. In IBM, vacuolated fibers or some other structurally abnormal fibers contained inclusions that were strongly immunoreactive for MKP-1. The MKP-1-positive inclusions were colocalized with ERK in dual fluorescence study. Inclusions of MKP-2 with less conspicuous than MKP-1 were found in some vacuolated fibers. Although diffusely increased Immunoreactivity of MKP-3 was found in some regenerating fibers, MKP-3 was negative in vacuolated fibers.

MKP-1 expression increases during the early stage of myogenesis, and regulates ERK at the stage of muscle specific gene expression (Bennett and Tonks 1997, Shi et al 2010). The findings indicating that regenerating fibers showed increased expression of MKP-1 are consistent with the experimental results. In ERK phosphorylation cascade, MKP-1 serves as a negative regulator of ERK (Robinson and Cobb 1997). Moreover, MKPs make a tight complex with their substrates when catalyzed. Thus, it is highly probable that MKP-1 is induced to inactivate ERK in s-IBM vacuolated fibers.

\subsection{Conclusion of MAPK cascades study: abnormal deposition of nuclear proteins involved in myogenesis}

Nuclear migration of ERK is necessary for myogenic gene expression (Gredinger et al 1998). Based on the results of our MAPK cascade study, we hypothesize an inhibition of protein transport from the cytoplasm into the nucleus. In s-IBM muscle fibers, normal levels of activation of ERK phosphorylation cascade may proceed down to MKK1/2, the activations of which occur on the plasma membrane or in the cytoplasm, triggered by myogenic or other stimulation in s-IBM-vacuolated fibers. Moreover, frequent perinuclear accumulation of ERK protein in vacuolated fibers suggests that the nuclear translocation of ERK is inhibited. Due to aggregation of ERK, the ERK protein might accumulate in the cytoplasm and become unable to move across the nuclear envelope. Otherwise, due to impaired nuclear transmigration of ERK protein, it could deposit in the cytoplasm and perinuclear region. Activated ERK phosphorylates its nuclear substrates probably immediately after its synthesis and forms complexes in the cytoplasm. The abnormal activation of ERK could induce MKP-1. These enzyme-substrate complexes further congregate together in the cytoplasm. The protein complexes might grow to the "aggresomes" in the perinuclear region to process the aggregates with extralysosomal protein degradation system (Johnston et al 1999). Some of the components of aggresomes were indeed found in s-IBM muscle fibers (Ferrer et al 2005).

Nuclear transport of ERK is a mediated process. This process is required for the induction of many cellular responses, yet the molecular mechanisms that regulate ERK nuclear translocation are not fully understood (Lidke et al 2010). In s-IBM, presence of specific antibodies against the nucleus has been shown (Dalakas et al 1997). Sera from patients with s-IBM and other idiopathic inflammatory myopathies sometimes contain antibodies against nuclear enzymes and components (Brouwer et al 2001). Furthermore, several autoimmune-diseases are associated with autoantibodies against chaperone proteins as well as well-known anti-nuclear antibodies (Corrigall et al 2001). In experiment, injection of antibodies against a heat shock cognate protein 70 that assists nuclear transport results in cytoplasmic accumulation of several nuclear proteins in human cell cultures (Imamoto 
et al 1992). Inhibition of carrier proteins or nuclear pore proteins involved in the nuclear transport results in the cytoplasmic and perinuclear accumulation of the cargo proteins (Görlich and Mattaj 1996). It is, therefore, suggested that a certain autoimmune mechanism could affect molecules involved in nuclear transport of ERK and induce cytoplasmic accumulation of ERK and its associated proteins in vacuolated fibers in IBM. Apart from autoimmune mechanism, nuclear envelope dysfunction could be aggravated by reactive oxygen species induced by inflammatory cytokines and by aging, as we will discuss them later.

Lack of proper nuclear migration of ERK inhibits MyoD expression (Gredinger et al 1998). Furthermore, forced induction of MKP-1 during myotube formation prevents myoblast fusion when the expression of the myosin heavy chain has occurred (Bennett and Tonks 1997). It is suggested that in s-IBM, there is an altered program of myogenesis due to abnormal aggregation of nuclear proteins that are associated with the differentiating process of muscle. The aggregation in turn may induce the protein degradation system, such as proteasmal pathways (Ferrer et al 2004) and autophagy (Kumamoto et al 2004), both of which are increased in s-IBM muscle fibers.

Our earlier report has shown CDK5-positive deposits in vacuolated fibers in s-IBM. A high proportion of the CDK5-positive deposits were perinuclear, as ERK. CDK5 co-localized with SMI-31 reactive deposits as ERK (Nakano et al 1999). CDK5, like ERK, belongs to the proline-directed kinases which can phosphorylate serine or threonine followed by proline sequences. CDK5 transiently appears in the nucleus during the terminal differentiation and promotes the process (Lazaro et al 1997). Thus, two protein kinases ERK and CDK5, both normally activated and translocated into the nucleus during the terminal phase of differentiation, accumulate in the cytoplasm and around the nuclei in s-IBM vacuolated fibers. We therefore hypothesize that the induction of ERK and CDK5 is part of the intrinsic program of muscle fiber differentiation, and one possibility is that the abnormally high concentration of these enzymes results from their aggregation in the cytoplasm and inability to enter the nucleus.

\section{Nuclear abnormality in S-IBM: history}

Several studies have shown distinct myonuclear alterations in s-IBM before establishing its nosology. In ultrastructural study, filamentous inclusions were sometimes detected in myonuclei as well as in the cytoplasm (Chou 1967). These inclusions in rare occasion appeared to be released from nuclei into the cytoplasm with breaks in the nuclear membrane. In s-IBM, but not in controls, myonuclei accumulate an unidentified a single stranded DNA-binding protein (Nalbantoglu et al 1994). Most of the sites of binding were myonuclei, whereas some were rimmed vacuoles. The figures suggest that rimmed vacuoles probably result from nuclear breakdown. Recent studies added valosin-containing protein (VCP) (Greenberg et al 2007b) and TDP-43 (Salajegheh et al 2009) to the list of proteins localized in both nuclear and rimmed vacuoles, supporting the hypothesis that nuclear breakdown results in rimmed vacuoles.

As our phosphoprotein study suggested the nuclear alterations in s-IBM vacuolated fibers, we thought to identify elemental components in rimmed vacuoles. If rimmed vacuoles originate from the nucleus, the basophilic components associated with them should be some components of the nucleus. Histones are representative of the basophilic substances, which prompted us to investigate histones in s-IBM. 
While our preparation of papers with histone H1, another group showed existence of nuclear membrane protein emerin and lamin A/C within rimmed vacuoles (Greenberg et al 2006)

\section{Immunolocalization study of histones in sporadic inclusion body myositis (s-IBM)}

\subsection{Histones and dynamic function of histone $\mathrm{H} 1$}

In inactive chromatin, the DNA is combined to histones and forms nucleosomes. A nucleosome is an octamer of four pairs of the core histones H2A, H2B, H3 and H4. Doublestranded DNA twines around nucleosomes. Histone H1 binds to the linker DNA that connects the individual nucleosomes. Among histones, histone $\mathrm{H} 1$ shows dynamic behavior to regulate chromatin folding and gene expression, while core histones are integral components of chromatin fibers (Bustin et al 2005). The H1 binding to linker DNA is essential for the generation of the highly condensed chromatin structure and plays a pivotal role in gene regulation (Brown 2003). H1 is rich in arginine and lysine residues, which makes it highly basic (Woodcock et al 2006).

\subsection{Histone H1, but not core histones (H2A, H2B, H3 and H4), are associated with rimmed vacuoles}

Figure 4 displays the results in triple-fluorescence study of histone H1, emerin (a nuclear envelope protein associated with inner nuclear membrane) and DAPI (a marker of nuclear DNA). After the fluorescence studies, the same sections are stained with H\&E as shown in the right column. The figures clearly show rimmed vacuole are products of nuclear degeneration. They reveal several modes of nuclear alterations. 1) H1-positive rings or deposits are associated with the nuclear membrane protein and DNA. Strong vacuolar H1positive reaction colocalized with a DNA ring is detected inside or on emerin-positive reaction in a proportion of vacuoles. The figures suggest swelling or ballooning of nuclei with scarce nuclear matrix proteins. 2) H1-positive reaction that appeared to be leaking beyond emerin-positive lines is found in some other vacuoles. The cytoplasmic release of H1 is also observed in some morphologically intact nuclei (Nakano et al 2008). The H\&E after the fluorescence study showed that $\mathrm{H} 1$ or emerin-positive products in vacuoles often appeared to correspond to the basophilic lines in H\&E. A region of cytoplasmic H1-positive reaction usually corresponded to basophilic lakes around vacuoles or nuclei in H\&E. The results indicated that release of $\mathrm{H} 1$ occurs even in an early phase of nuclear breakdown. In contrast, although regenerating fibers show increased H1 reactivity in their large and vesicular nuclei, H1-positive products fall within these nuclei. Calculation indicated that approximately $60 \%$ of vacuolated fibers contained H1-positive rings or other H1-positive remnants (Nakano et al 2008). Conversely, immunohistochemistry of histones H2A, H2B, $\mathrm{H} 3$ and $\mathrm{H} 4$ showed rare vacuoles harbored positive deposits. The comparative study with immunofluorescence and subsequent H\&E staining suggested that histone H1 and other nuclear proteins comprise basophilic granules in rimmed vacuoles.

\subsection{Cytoplasmic release of histone $\mathrm{H} 1$ suggests DNA double strand breaks}

Cytoplasmic release of H1, but not other histones, has been observed in a type of apoptosis in an experimental study of cultured human cells: apoptosis induced by stimuli causing DNA double strand breaks such as X-ray irradiation, but not other apoptotic stimuli, 


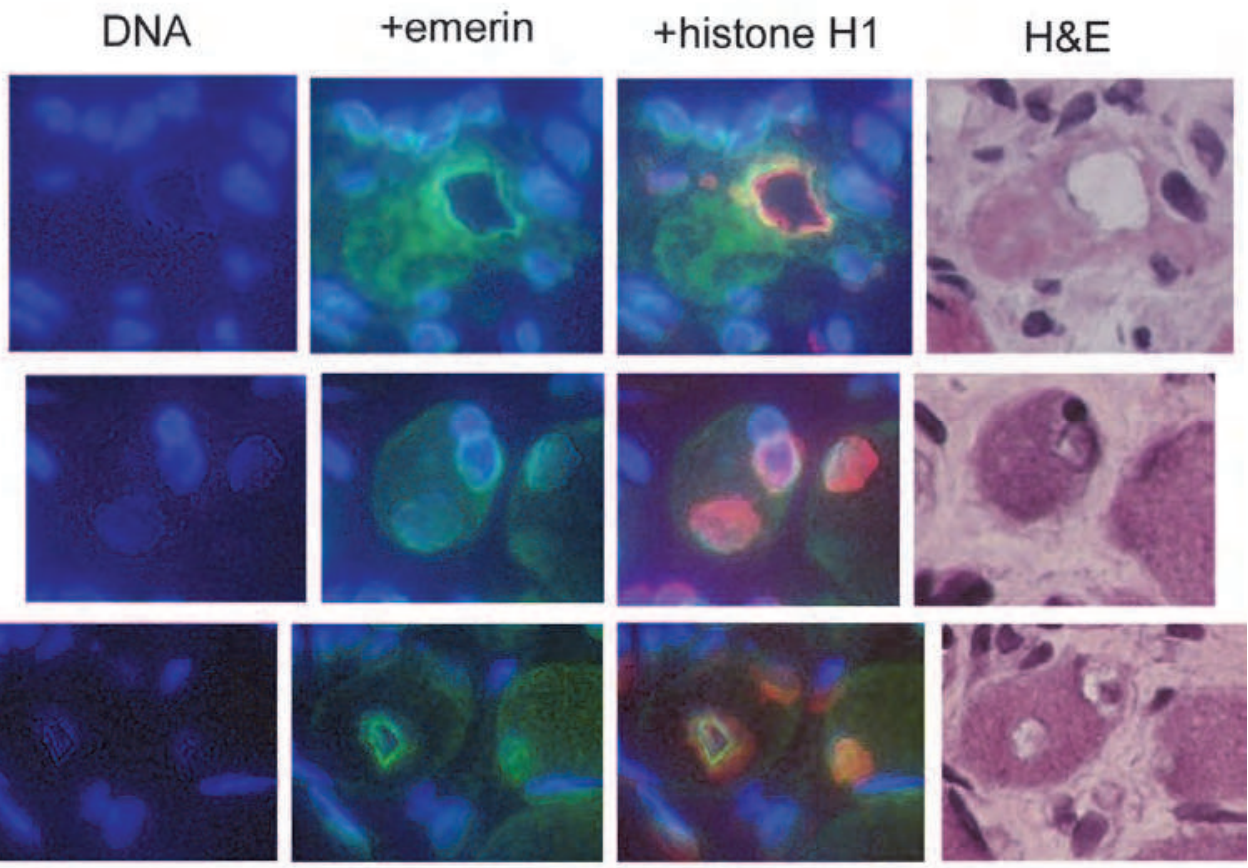

Fig. 4. Triple fluorescence studies in s-IBM vacuolated fibers. Blue: nuclear DNA; Green: emerin; Red: histone H1. Vacuoles usually appear to be more accentuated in H\&E, probably due to dehydration process. The background green colour is purposely heightened to visualize muscle fibers.

releases histone H1 into the cytoplasm (Konishi et al 2003). Therefore, the cytoplasmic H1 release in s-IBM might indicate that some apoptotic stimuli causing DNA double strand breaks induce the s-IBM pathology. Apoptotic process exemplified by TUNEL revealed that it may scarcely operate in s-IBM muscle fibers (Hutchinson 1998). Nevertheless, several studies displayed some players of apoptosis in s-IBM muscle fibers (Behrens et al 1997, Li and Dalakas 2000b)

\section{DNA double strand breaks (DSB) in S-IBM}

\subsection{The DNA damage responses}

The primary structure of DNA is constantly exposed to cellular metabolites and extracellular DNA-damaging agents. These alterations can affect the cell to transcription of the genes. Other lesions induce potentially harmful mutations. Consequently, the DNA repair process must be constantly activated to respond to the damages in the DNA structure. Defects of the repair processes may cause genomic instability. To repair damage to one of the two paired molecules of DNA, there are many excision repair mechanisms that remove the damaged nucleotide and replace it with an undamaged nucleotide complementary to that found in the undamaged DNA strand. The examples of these are base excision repair, nucleotide excision repair, and DNA mismatch repair. 
DNA double strand breaks (DSB), in which both strands in the double helix are severed, are particularly serious to the cell because they can lead to genome rearrangements. DSB are produced by reactive oxygen species, ionizing radiation, chemicals that generate reactive oxygen species and replication error. DSB are also a normal result of $\mathrm{V}(\mathrm{D}) \mathrm{J}$ recombination and immunoglobulin class-switching process. DSB are repaired either by homologous recombination (HR) or nonhomologous end-joining (NHEJ) mechanism (O'Driscol and Jeggo 2006). HR plays only in replicating cells, while NHEJ functions in both cells in the cell cycle and those terminally differentiated. Mature muscle cells are terminally differentiated cells, that is, the cells withdraw from the cell replication cycle. Terminally differentiated cells do not possess a replication-associated DNA repair mechanism (HR mentioned above). This lack makes the terminally differentiated cells particularly sensitive to DNA damage (Lee and McKinnon 2007). In a muscle cell culture study, the exposure of differentiated myocytes to hydrogen peroxide, which induces reactive oxygen species, resulted in the accumulation of foci of DSB. It is exemplified by immunolocalization of phosphorylated histone H2AX $(\gamma-$ $\mathrm{H} 2 \mathrm{AX}$ ) (Narciso et al 2007). The detection of $\gamma-\mathrm{H} 2 \mathrm{AX}$ is a sensitive marker of DSB (Nakamura 2006). Histone H2AX that is a variant of histone H2A is rapidly phosphorylated at Ser 139 in the chromatin region surrounding a DSB (Kinner 2008). Immunocytochemical staining of $\gamma-\mathrm{H} 2 \mathrm{AX}$ has been broadly applied to reveal DNA damage caused by cancer and other cellular stresses (Nakamura 2006, Kinner 2008).

DSB is different from the apoptotic DNA fragmentation that has been residually detected in the s-IBM muscles (Hutchinson 1998). In DSB, DNA breaks are induced directly and randomly by radiation or other genotoxic agents, whereas apoptotic DNA fragmentation occurs at a late stage of programmed cell death, when endonucleases sever DNA strands at regular lengths, making a ladder formation in Southern blotting.

DNA-PK is an enzyme involved in the initial step of the DSB repair process NHEJ, which does not require DNA replication, and therefore NHEJ is the major DNA repair mechanism in terminally differentiated cells (O'Driscoll and Jeggo 2006, Mahaney et al 2009). DNA-PK consists of a catalytic subunit (DNA-PKcs) and two regulatory subunits (Ku70 and Ku80). The binding of hetero-duplexes of Ku70 and Ku80 to DSB sites initiates the repair process (Mari et al 2006, Weterings and Chen 2007).

We immunolocalized $\gamma-\mathrm{H} 2 \mathrm{AX}$ in s-IBM and we also tested DNA-PK to see whether the repair mechanism is defective or not (Nishii et al 2011). In the study, vacuolar peripheries often showed strong immunoreactivity to $\gamma-\mathrm{H} 2 \mathrm{AX}$ and the three components of DNA-PK (DNA-PKcs, Ku70, and Ku80). The percentage of positive nuclei for $\gamma-\mathrm{H} 2 \mathrm{AX}$ was significantly higher in vacuolated fibers than non-vacuolated fibers in s-IBM, or fibers in polymyosits suggesting that nuclear breakdown occurs along with the accumulation of DSB in muscle cells in s-IBM. Moreover, a triple fluorescence study of Ku70, emerin, and DNA suggested impaired nuclear incorporation of Ku70. Nuclear translocation of Ku proteins is important for DBS repair, and a deficiency in nuclear translocation caused hypersensitivity against X-ray irradiation due to the lack of DBS repair in a cell culture study (Okui et al 2002). Therefore, we hypothesized that defects in Ku70 nuclear import accelerate DSB formation in s-IBM.

Despite DSB was the highest in S-IBM vacuolated fibers, DSB was sometimes found to be increased in myonuclei without nuclear breakdown. Therefore, additional factors may be involved in the nuclear breakdown detected in s-IBM. We consider that a dysfunction of nuclear envelope may explain all the alterations in s-IBM: 1) nuclear fragility; 2) DNA double-strand breaks; and 3) impaired nuclear transport in s-IBM. 
Impaired DSB results growth arrest, senescence, and apoptosis (Rossetto et al 2010). Our earlier examination showed aberrant expressions of proteins associated with myogenic differentiation. In s-IBM, the accumulation of DSB could result in arrest of muscle fiber maturation.

\section{Possible mechanism of nuclear breakdown}

Nuclear envelope dysfunction can cause both mechanical fragility of the nucleus and DNA damage. Lamins are proteins of nuclear intermediate filaments that comprise the lamina, the meshwork supporting inner nuclear membranes. Mutations in the genes that encode lamins and emerin cause Emery-Dreifuss muscular dystrophy and a number of different diseases collectively called laminopathies (Capell and Collins 2006). In several laminopathies, blebbing of the nuclei in cultured fibroblasts can be seen, and it is hypothesized that such mutations result in fragile and mechanically unstable nuclei (Goldman et al 2004). Indeed, emerin mutations can cause myopathy with rimmed vacuoles (Paradas et al 2005, Fidziańska et al 2004). Besides structural integrity, the lamina is also involved in various other processes, such as replication and gene transcription, which are intimately associated with DNA damage repair. Accordingly, impaired DNA repair has been found in several laminopathies. Fibroblasts possessing a laminopathy mutation show an excessive amount of un-repaired DNA damage, as exemplified by $\gamma-\mathrm{H} 2 \mathrm{AX}$ immunohistochemistry (Liu et al 2005). 3) Furthermore, lamins are important in the spatial rearrangement of nuclear pore complexes and therefore nuclear protein transport. Nuclear protein import is reduced in cells expressing lamin A mutants (Busch et al 2009). We repeatedly detected figures suggestive of impaired nuclear import of proteins, as has been described in our phosphorylated protein study.
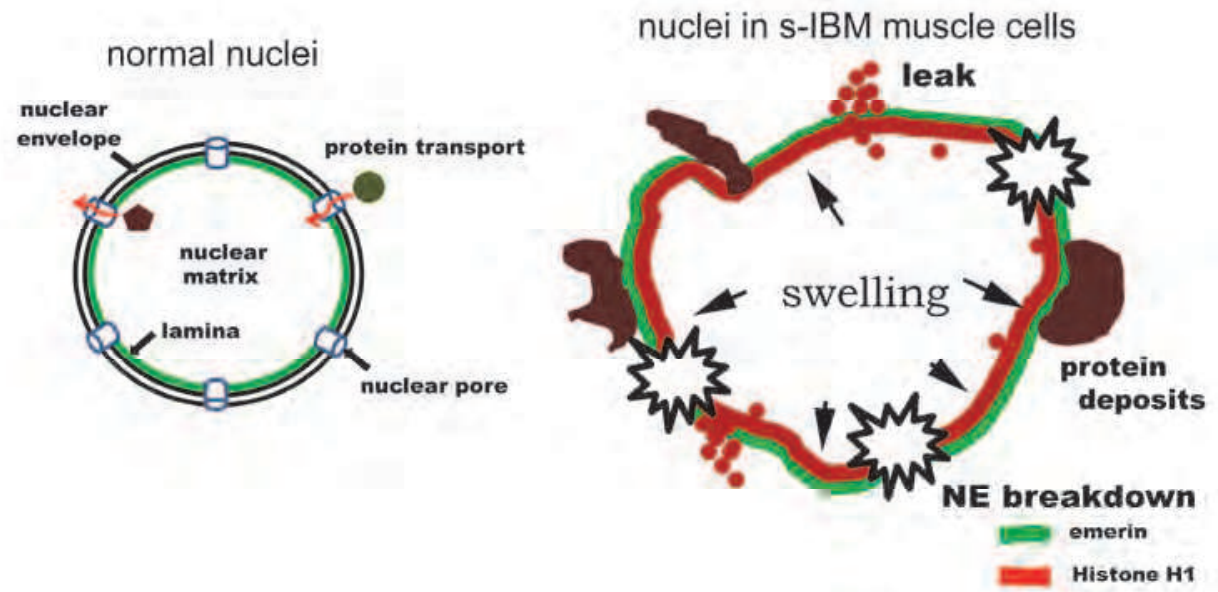

Fig. 5. Simplified schema of normal nuclei and nuclei in s-IBM muscle fibers. In s-IBM, nuclear proteins deposits occur in perinuclear regions due to inhibition of nuclear import, whereas histone $\mathrm{H} 1$ is released from nnclei. Finally, the nuclear envelopes break down to form rimmed vacuoles. 
To summarize, dysfunctional lamins can explain the nuclear breakdown, accumulation of DSB, and impaired nuclear transport observed in s-IBM. As discussed in the section about perinuclear deposition of protein kinases, autoimmune mechanism could operate in the dysfunction of nuclear envelope. In addition, aging might increase the nuclear vulnerability and DNA damage. Nuclear pore complexes are not turned over in differentiated cells, and age-related alterations in nuclear pore complexes have been shown. Leaking of nuclear matrix proteins is dramatically accelerated during aging and that a subset of nucleoporins (components of nuclear pores) is oxidatively damaged in old cells (D'Angelo et al 2009). Moreover, several studies have indicated an age-dependent decline in DNA repair capacity (Gorbunova et al 2007). We suspect that these age-associated changes in nuclear envelope function and DNA repair mechanisms may predispose the muscles of the elderly to s-IBM pathology.

\section{Similarity of s-IBM and DMRV/h-IBM}

We found inclusions of a set of nucleus-oriented or nucleus-proper proteins in distal myopathy with rimmed vacuoles (DMRV)/hereditary inclusion body myopathy (h-IBM), a disorder in which the muscle biopsy displays rimmed vacuoles in muscle fibers as in s-IBM (Fig. 6) (Nakano et al 1999, 2001, 2003, 2008).
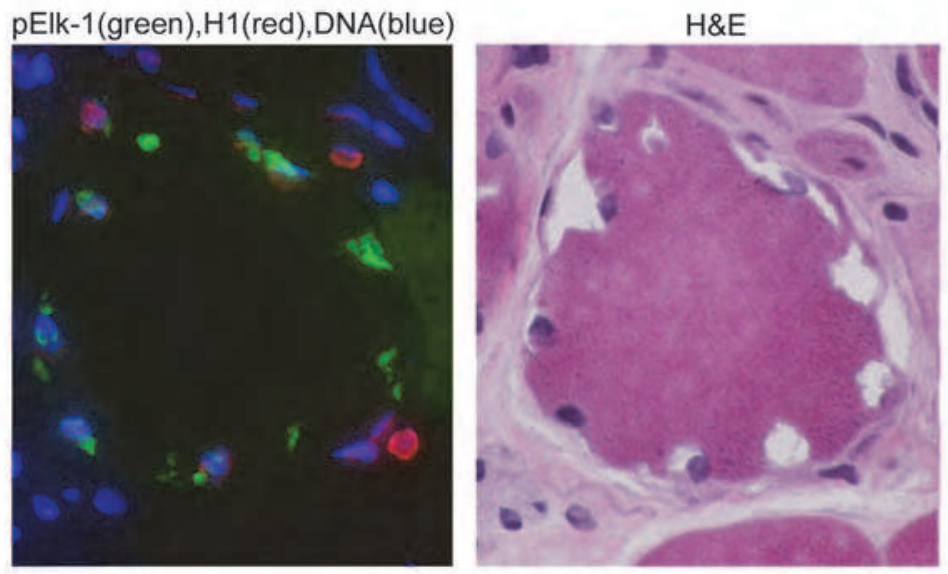

Fig. 6. Immunohistochemistry of pElk-1 and histone H1 in DMRV/h-IBM. Many pElk-1positive deposits are seen in vacuoles .

Muscle pathology of DMRV/s-IBM shows rimmed vacuoles and tubulofilaments like s-IBM, but it lacks inflammation. The mutated gene for this autosomal recessive disease has been identified to be involved in glycosylation, named UDP-N-acetylglucosamine 2epimerase/N-acetylmannosamine kinase (GNE) (Eisenberg et al 2001, Nishino et al 2002). Remarkably, N-acetylglucosamine, the substrate of this enzyme is also a substrate of UDP$\mathrm{N}$-acetylglucosamine:polypeptide $\beta$-N-acetylglucosaminyl transferase (OGT), the enzyme that adds O-linked- $\beta-\mathrm{N}$-acetylglucosamine (O-GlcNAc) to a protein. A thousand of proteins including transcription factors, cytoskeletal proteins, kinases and nuclear pore proteins are modified with O-GlcNAc (Zachara and Hart 2004). O-GlcNAc is a highly dynamic process 
and acts as a modulator of protein function, in a manner analogous to protein phosphorylation. Moreover, there is a complex crosstalk between O-GlcNAc modification and phosphorylation. The two post-translational modifications often regulate in an opposite manner by competitive attachment to the same serine/threonine residue, but they sometimes function co-operatively by binding at different sites of the same molecule (Zeidan 2010). In DMRV/h-IBM as well as in s-IBM, abnormal expression of proteins concerning to phosphorylation could be related to perturbation of the O-GlcNAc modification of proteins.

\section{Conclusion}

We have examined myonuclear dysfunction s-IBM. Similar degenerative mechanism may exist in DMRV/h-IBM that shows almost identical pathology and nuclear breakdown concerning to muscle fiber degeneration (Nonaka et al 1998). To reveal how GNE enzyme dysfunction affects myonuclei in this disorder may contribute to unveil the etiology of sIBM. In addition, myofibrillar myopathy is a genetic disorder in which mutations of several Z-line associated proteins have been identified. Muscle biopsy studies have found congophilic inclusions (Selcen and Engel 2010). Players involved in excessive protein processing have been detected in s-IBM and myofibrillar myopathy (Ferrer et al 2004, 2005). Moreover, the disorder sometimes accompanies rimmed vacuoles (Shinde et al 2008). The comparative study of s-IBM and myofibrillar myopathy may also be helpful.

Concerning to the relationship between inflammation and nuclear breakdown, some immunological mechanism could operate in nuclear envelope dysfunction. Otherwise, nuclear aging and decrease of DNA repair capacity due to aging could induce the nuclear degeneration.

\section{Acknowledgment}

This work was supported in part by Grant-in-Aids from the Japan Society for the Promotion of Science and from the Ministry of Health, Labour, and Welfare for Research on intractable diseases.

\section{References}

Askanas V, Engel WK, Alvarez RB. Light and electron microscopic localization of betaamyloid protein in muscle biopsies of patients with inclusion-body myositis. Am J Pathol. 1992 Jul;141(1):31-6.

Askanas V, Engel WK, Bilak M, Alvarez RB, Selkoe DJ. Twisted tubulofilaments of inclusion body myositis muscle resemble paired helical filaments of Alzheimer brain and contain hyperphosphorylated tau. Am J Pathol 1994;144:177-187.

Askanas V, Engel WK. Inclusion-body myositis: muscle-fiber molecular pathology and possible pathogenic significance of its similarity to Alzheimer's and Parkinson's disease brains. Acta Neuropathol. 2008 Dec;116(6):583-95.

Banker B, Engel AG. Basic reactions of muscle. In: Engel AG, Franzini-Armstrong C, ed. Myology. 2nd ed. New York, NY: McGraw-Hill, 1994: 832-888.

Behrens L, Bender A, Johnson MA, Hohlfeld R. Cytotoxic mechanisms in inflammatory myopathies. Co-expression of Fas and protective $\mathrm{Bcl}-2$ in muscle fibres and inflammatory cells. Brain. 1997 Jun;120 ( Pt 6):929-38. 
Bennett A, Tonks NK. Regulation of distinct stages of skeletal muscle differentiation by mitogen-activated protein kinases. Science 1997;278:1288-1291.

Brouwer R, Hengstman GJ, Vree Egberts W, Ehrfeld H, Bozic B, Ghirardello A, Grøndal G, Hietarinta M, Isenberg D, Kalden JR, Lundberg I, Moutsopoulos H, Roux-Lombard P, Vencovsky J, Wikman A, Seelig HP, van Engelen BG, van Venrooij WJ. Autoantibody profiles in the sera of European patients with myositis. Ann Rheum Dis 2001;60:116-123.

Brown DT. Histone H1 and the dynamic regulation of chromatin function. Biochem Cell Biol 2003;81:221-227.

Busch A, Kiel T, Heupel WM, Wehnert M, Hübner S. Nuclear protein import is reduced in cells expressing O-GlcNAc nuclear envelopathy-causing lamin A mutants. Exp Cell Res 2009;315:2373-2385.

Bustin M, Catez F, Lim JH. The dynamics of histone H1 function in chromatin. Mol Cell 2005;17:617-620.

Capell BC, Collins FS. Human laminopathies: nuclei gone genetically awry. Nat Rev Genet 2006;7:940-952.

Carpenter S, Karpati G, Wolfe L. Virus like filaments and phospholipid accumulations in a case of chronic myopathy. J Neuropathol Exp Neurol. 1971 Jan;30(1):136-7.

Carpenter S, Karpati G, Heller I, Eisen A. Inclusion body myositis: a distinct variety of idiopathic inflammatory myopathy. Neurology. 1978 Jan;28(1):8-17.

Chou SM. Myxovirus-like structures in a case of human chronic polymyositis. Science. 1967 Dec 15;158(807):1453-5.

Corrigall VM, Bodman-Smith MD, Fife MS, Canas B, Myers LK, Wooley P, Soh C, Staines NA, Pappin DJ, Berlo SE, van Eden W, van Der Zee R, Lanchbury JS, Panayi GS. The human endoplasmic reticulum molecular chaperone BiP is an autoantigen for rheumatoid arthritis and prevents the induction of experimental arthritis. J Immunol 2001;166:1492-1498.

Dalakas M, Illa I, Gallardo E, Juarez C. Inclusion body myositis and paraproteinemia: Incidence and immunopathologic correlations. Ann Neurol 1997;41:100-104.

Dalakas MC. Sporadic inclusion body myositis--diagnosis, pathogenesis and therapeutic strategies. Nat Clin Pract Neurol 2006;2:437-447.

D'Angelo MA, Raices M, Panowski SH, Hetzer MW. Age-dependent deterioration of nuclear pore complexes causes a loss of nuclear integrity in postmitotic cells. Cell. 2009 Jan 23;136(2):284-95.

Dubiwitz V, Sewry CA. Metabolic myopathies I: Glycogenosis. Muscle biopsy. 3rd ed., Sanders/Elsevier 2007: pp 453-468

Eisenberg I, Avidan N, Potikha T, Hochner H, Chen M, Olender T, Barash M, Shemesh M, Sadeh M, Grabov-Nardini G, Shmilevich I, Friedmann A, Karpati G, Bradley WG, Baumbach L, Lancet D, Asher EB, Beckmann JS, Argov Z, Mitrani-Rosenbaum S. The UDP-N-acetylglucosamine 2-epimerase/N-acetylmannosamine kinase gene is mutated in recessive hereditary inclusion body myopathy. Nat Genet. 2001 Sep;29(1):83-7.

Ferrer I, Carmona M, Blanco R, Moreno D, Torrejón-Escribano B, Olivé M. Involvement of clusterin and the aggresome in abnormal protein deposits in myofibrillar myopathies and inclusion body myositis. Brain Pathol. 2005;15(2):101-8.

Ferrer I, Martín B, Castaño JG, Lucas JJ, Moreno D, Olivé M. Proteasomal expression, induction of immunoproteasome subunits, and local MHC class I presentation in myofibrillar myopathy and inclusion body myositis. J Neuropathol Exp Neurol. 2004 May;63(5):484-98. 
Fidziańska A, Rowińska-Marcińska K, Hausmanowa-Petrusewicz I. Coexistence of X-linked recessive Emery-Dreifuss muscular dystrophy with inclusion body myositis-like morphology. Acta Neuropathol 2004;107:197-203.

Force T, Bonventre JV. Growth factors and mitogen-activated protein kinases. Hypertension 1998; 31: 152-161.

Goldman RD, Shumaker DK, Erdos MR, et al. Accumulation of mutant lamin A causes progressive changes in nuclear architecture in Hutchinson-Gilford progeria syndrome. Proc Natl Acad Sci U S A 2004;101:8963-8968.

Gorbunova V, Seluanov A, Mao Z, Hine C. Changes in DNA repair during aging. Nucleic Acids Res 2007;35:7466-7474.

Görlich D, Mattaj IW. Nucleocytoplasmic transport. Science 1996; 271: 1513-1518.

Gredinger E, Gerber AN, Tamir Y, Tapscott SJ, Bengal E. Mitogen-activated protein kinase pathway is involved in the differentiation of muscle cells. J Biol Chem 1998;273:10436-10444.

Greenberg SA, Pinkus JL, Amato AA. Nuclear membrane proteins are present within rimmed vacuoles in inclusion-body myositis. Muscle Nerve 2006;34:406-416.

Greenberg SA, Pinkus GS, Amato AA, Pinkus JL. Myeloid dendritic cells in inclusion-body myositis and polymyositis. Muscle Nerve. 2007a Jan;35(1):17-23.

Greenberg SA, Watts GD, Kimonis VE, Amato AA, Pinkus JL. Nuclear localization of valosin-containing protein in normal muscle and muscle affected by inclusion-body myositis. Muscle Nerve. 2007b Oct;36(4):447-54.

Greenberg SA. How citation distortions create unfounded authority: analysis of a citation network. BMJ. 2009 Jul 20;339:b2680.

Griggs RC, Askanas V, DiMauro S, Engel A, Karpati G, Mendell JR, Rowland LP. Inclusion body myositis and myopathies. Ann Neurol 1995;38:705-713.

Grounds M. Muscle regeneration: molecular aspects and therapeutic implications. Curr Opin Neurol 1999;12:353-543.

Hartlerode AJ, Scully R. Mechanisms of double-strand break repair in somatic mammalian cells. Biochem J. 2009 Sep 25;423(2):157-68.

Hill C, Treisman R. Transcriptional regulation by extracellular signals: mechanisms and specificity. Cell 1995; 80: 199-211.

Hunter T, Karin M. The regulation of transcription by phosphorylation. Cell.1992 Aug 7;70(3):375-87.

Hutchinson DO. Inclusion body myositis: abnormal protein accumulation does not trigger apoptosis. Neurology. 1998 Dec;51(6):1742-5.

Imamoto N, Matsuoka Y, Kurihara T, Kohno K, Miyagi M, Sakiyama F, Okada Y,Tsunasawa $\mathrm{S}$, Yoneda Y. Antibodies against 70-kD heat shock cognate protein inhibit mediated nuclear import of karyophilic proteins. J Cell Biol 1992; 119: 1047-1061

Johnston JA, Ward CL, Kopito RR. Aggresomes: a cellular response to misfolded proteins. J Cell Biol 1998; 143:1883-1898.

Keyse S. Protein phosphatases and the regulation of mitogen-activated protein kinase signalling. Curr Opin Cell Biol 2000;12:186-192.

Kinner A, Wu W, Staudt C, Iliakis G. Gamma-H2AX in recognition and signaling of DNA double-strand breaks in the context of chromatin. Nucleic Acids Res 2008;36:56785694.

Konishi A, Shimizu S, Hirota J, Takao T, Fan Y, Matsuoka Y, Zhang L, Yoneda Y, Fujii Y, Skoultchi AI, Tsujimoto Y. Involvement of histone H1.2 in apoptosis induced by DNA double-strand breaks. Cell 2003;114:673-688 
Kumamoto T, Ueyama H, Tsumura H, Toyoshima I, Tsuda T. Expression of lysosomerelated proteins and genes in the skeletal muscles of inclusion body myositis. Acta Neuropathol. 2004 Jan;107(1):59-65.

Kyriakis J, Avruch J. Mammalian mitogen-activated protein kinase signal transduction pathways activated by stress and inflammation. Physiol Rev 2001;81:807-869.

Lazaro J, Kitzmann M, Poul MA, Vandromme M, Lamb NJ, Fernandez A. Cyclin dependent kinase 5, cdk5, is a positive regulator of myogenesis in mouse C2 cells. J Cell Sci 1997; 110: 1251-1260.

Lee Y, McKinnon PJ. Responding to DNA double strand breaks in the nervous system. Neuroscience 2007;145:1365-1374.

Li J, Johnson SE. ERK2 is required for efficient terminal differentiation of skeletal myoblasts. Biochem Biophys Res Commun. 2006 Jul 14;345(4):1425-33.

Li M, Dalakas MC. The muscle mitogen-activated protein kinase is altered in sporadic inclusion body myositis. Neurology. 2000a Apr 25;54(8):1665-70.

Li M, Dalakas MC. Expression of human IAP-like protein in skeletal muscle: a possible explanation for the rare incidence of muscle fiber apoptosis in T-cell mediated inflammatory myopathies. J Neuroimmunol. 2000b Jul 1;106(1-2):1-5.

Lidke DS, Huang F, Post JN, Rieger B, Wilsbacher J, Thomas JL, Pouysségur J, Jovin TM, Lenormand P. ERK nuclear translocation is dimerization-independent but controlled by the rate of phosphorylation. J Biol Chem. 2010 Jan 29;285(5):3092-102.

Liu B, Wang J, Chan KM, Tjia WM, Deng W, Guan X, Huang JD, Li KM, Chau PY, Chen DJ, Pei D, Pendas AM, Cadiñanos J, López-Otín C, Tse HF, Hutchison C, Chen J, Cao Y, Cheah KS, Tryggvason K, Zhou Z. Genomic instability in laminopathy-based premature aging. Nat Med 2005;11:780-785.

Lluís F, Perdiguero E, Nebreda AR, Muñoz-Cánoves P. Regulation of skeletal muscle gene expression by p38 MAP kinases. Trends Cell Biol. 2006 Jan;16(1):36-44.

Lotz BP, Engel AG, Nishino H, Stevens JC, Litchy WJ. Inclusion body myositis. Observations in 40 patients. Brain. 1989 Jun;112 ( Pt 3):727-47."

Lundberg I, Ulfgren A, Nyberg P,Andersson U, Klarreskog L. Cytokine production in muscle tissue of patients with idiopathic inflammatory myopathies. Arth Rheum 1997;40:865-874.

Lünemann JD, Schmidt J, Schmid D, Barthel K, Wrede A, Dalakas MC, Münz C. Betaamyloid is a substrate of autophagy in sporadic inclusion body myositis. Ann Neurol. 2007 May;61(5):476-83.

Mahaney BL, Meek K, Lees-Miller SP. Repair of ionizing radiation-induced DNA doublestrand breaks by non-homologous end-joining. Biochem J 2009;417:639-650.

Maurage CA, Bussière T, Sergeant N, Ghesteem A, Figarella-Branger D, Ruchoux MM, Pellissier JF, Delacourte A. Tau aggregates are abnormally phosphorylated in inclusion body myositis and have an immunoelectrophoretic profile distinct from other tauopathies. Neuropathol Appl Neurobiol. 2004 Dec;30(6):624-34.

Mari PO, Florea BI, Persengiev SP, Verkaik NS, Brüggenwirth HT, Modesti M, Giglia-Mari G, Bezstarosti K, Demmers JA, Luider TM, Houtsmuller AB, van Gent DC. Dynamic assembly of end-joining complexes requires interaction between Ku70/80 and XRCC4. Proc Natl Acad Sci U S A 2006;103:18597-18602.

Mendell JR, Sahenk Z, Gales T, Paul L. Amyloid filaments in inclusion body myositis. Novel findings provide insight into nature of filaments. Arch Neurol. 1991 Dec;48(12):1229-34.

Mirabella M, Alvarez RB, Bilak M, Engel WK, Askanas V. Difference in expression of phosphorylated tau epitopes between sporadic inclusion-body myositis and 
hereditary inclusion-body myopathies. J Neuropathol Exp Neurol. 1996 Jul;55(7):774-86.

Nakamura A, Sedelnikova OA, Redon C, Pilch DR, Sinogeeva NI, Shroff R, Lichten M, Bonner WM. Techniques for gamma-H2AX detection. Methods Enzymol 2006;409:236-250.

Nakano S, Akiguchi I, Nakamura S, Satoi H, Kawashima S, Kimura J. Aberrant expression of cyclin-dependent kinase 5 in inclusion body myositis. Neurology 1999; 53: 16711676.

Nakano S, Kawashima S, Satoi H, et al. Active form of ERK2 is a major phosphorylated protein in vacuolated fibers in sporadic inclusion body myositis. Muscle \& Nerve 1998; S130. Abstract.

Nakano S, Shinde A, Ito H, Ito H, Kusaka H. MAP kinase phosphatase-1 is induced in abnormal fibers in inclusion body myositis. Neurology. 2003 Aug 12;61(3): 322-6.

Nakano S, Shinde A, Kawashima S, Nakamura S, Akiguchi I, Kimura J. Inclusion body myositis:expression of extracellular signal-regulated kinase and its substrate. Neurology. 2001 Jan 9;56(1):87-93.

Nakano S, Shinde A, Fujita K, Ito H, Kusaka H. Histone H1 is released from myonuclei and present in rimmed vacuoles with DNA in inclusion body myositis. Neuromuscul Disord 2008;18:27-33.

Nalbantoglu J, Karpati G, Carpenter S. Conspicuous accumulation of a single-stranded DNA binding protein in skeletal muscle fibers in inclusion body myositis. Am J Pathol 1994;144:874-882.

Narciso L, Fortini P, Pajalunga D, et al. Terminally differentiated muscle cells are defective in base excision DNA repair and hypersensitive to oxygen injury. Proc Natl Acad Sci U S A 2007;104:17010-17015.

Needham M, Mastaglia FL. Sporadic inclusion body myositis: a continuing puzzle. Neuromuscul Disord 2008;18:6-16.

Nishii M, Nakano S, Nakamura S, Wate R, Shinde A, Kaneko S, Kusaka H. Myonuclear breakdown in sporadic inclusion body myositis is accompanied by DNA double strand breaks. Neuromuscul Disord. 2011 May;21(5):345-52.

Nishino I, Noguchi S, Murayama K, et al. Distal myopathy with rimmed vacuoles is allelic to hereditary inclusion body myopathy. Neurology 2002;59:1689-1693.

Nonaka I, Murakami N, Suzuki Y, Kawai M. Distal myopathy with rimmed vacuoles. Neuromuscul Disord 1998; 8: 333-337.

Nukina N, Kosik KS, Selkoe DJ. Recognition of Alzheimer paired helical filaments by monoclonal neurofilament antibodies is due to crossreaction with tau protein. Proc Natl Acad Sci USA 1987; 84: 3415-3419.

O'Driscoll M, Jeggo PA. The role of double-strand break repair - insights from human genetics. Nat Rev Genet 2006;7:45-54.

Okui T, Endoh D, Kon Y, Hayashi M. Deficiency in nuclear accumulation of G22p1 and Xrcc5 proteins in hyper-radiosensitive Long-Evans Cinnamon (LEC) rat cells after $X$ irradiation. Radiat Res 2002;157:553-561.

Paradas C, Márquez C, Gallardo E, et al. X-linked Emery-Dreifuss muscular dystrophy and vacuoles: an immunohistochemical characterization. Muscle Nerve 2005;32:61-65.

Reffas S, Schlegel W. Compartment-specific regulation of extracellular signal-regulated kinase (ERK) and c-Jun N-terminal kinase (JNK) mitogen-activated protein kinases (MAPKs) by ERK-dependent and non-ERK-dependent inductions of MAPK 
phosphatase (MKP)-3 and MKP-1 in differentiating P19 cells. Biochem J 2000;352:701-708.

Robinson M, Cobb MH. Mitogen-activated protein kinase pathways. Curr Opin Cell Biol 1997;9:180-186.

Rossetto D, Truman AW, Kron SJ, Côté J. Epigenetic modifications in double-strand break DNA damage signaling and repair. Clin Cancer Res. 2010 Sep 15;16(18): 4543-52.

Salajegheh M, Pinkus JL, Taylor JP, et al. Sarcoplasmic redistribution of nuclear TDP-43 in inclusion body myositis. Muscle Nerve 2009a;40:19-31.

Salajegheh M, Pinkus JL, Nazareno R, Amato AA, Parker KC, Greenberg SA. Nature of "Tau" immunoreactivity in normal myonuclei and inclusion body myositis. Muscle Nerve. 2009b Oct;40(4):520-8.

Schillace R Scott JD. Organization of kinases, phosphatases, and receptor signaling complexes. J Clin Invest 2000;103:767-772.

Schmidt J, Barthel K, Wrede A, Salajegheh M, Bähr M, Dalakas MC. Interrelation of inflammation and APP in sIBM: IL-1 beta induces accumulation of beta-amyloid in skeletal muscle. Brain. 2008 May;131(Pt 5):1228-40.

Selcen D, Engel AG. Myofibrillar Myopathy. 2005 Jan 28 [updated 2010 Jul 27]. In: Pagon RA, Bird TD, Dolan CR, Stephens K, editors. GeneReviews [Internet]. Seattle (WA): University of Washington, Seattle; 1993-. Available from http:/ / www.ncbi.nlm.nih.gov/ bookshelf/br.fcgi?book=gene\&part=mfm

Sherriff FE, Joachim CL, Squier MV, Esiri MM. Ubiquitinated inclusions in inclusion-body myositis patients are immunoreactive for cathepsin D but not beta-amyloid. Neurosci Lett. 1995 Jul 14;194(1-2):37-40

Shi H, Scheffler JM, Pleitner JM, Zeng C, Park S, Hannon KM, Grant AL, Gerrard DE. Modulation of skeletal muscle fiber type by mitogen-activated protein kinase signaling. FASEB J. 2008 Aug;22(8):2990-3000.S

Shinde A, Nakano S, Sugawara M, Toyoshima I, Ito H, Tanaka K, Kusaka H. Expression of caveolar components in primary desminopathy. Neuromuscul Disord.2008 Mar;18(3):215-9.

Soulez M, Rouviere CG, Chafey P, et al. Growth and differentiation of C2 myogenic cells are dependent on serum response factor. Mol Cell Biol 1996; 11: 6065-6074.

Treisman R. Ternary complex factors: growth factor regulated transcriptional activators. Curr Opin Genet Dev 1994; 4: 96-101.

Weterings E, Chen DJ. DNA-dependent protein kinase in nonhomologous end joining: a lock with multiple keys? J Cell Biol 2007;179:183-186.

Woodcock CL, Skoultchi AI, Fan Y. Role of linker histone in chromatin structure and function: H1 stoichiometry and nucleosome repeat length. Chromosome Res 2006;14:17-25.

Zachara NE, Hart GW. O-GlcNAc a sensor of cellular state: the role of nucleocytoplasmic glycosylation in modulating cellular function in response to nutrition and stress. Biochim Biophys Acta. 2004 Jul 6;1673(1-2):13-28.

Zeidan Q, Hart GW. The intersections between O-GlcNAcylation and phosphorylation: implications for multiple signaling pathways. J Cell Sci. 2010 Jan 1;123(Pt 1):13-22.

Zetser A, Gredinger E, Bengal E. p38 mitogen-activated protein kinase pathway promotes skeletal muscle differentiation. J Biol Chem 1999; 274: 5193-5200. 


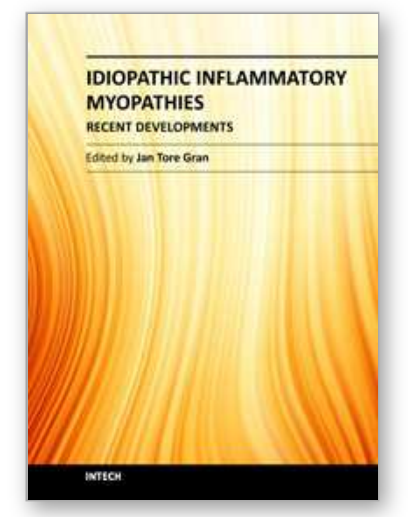

\author{
Idiopathic Inflammatory Myopathies - Recent Developments \\ Edited by Prof. Jan Tore Gran
}

ISBN 978-953-307-694-2

Hard cover, 212 pages

Publisher InTech

Published online 15, September, 2011

Published in print edition September, 2011

The term "myositis" covers a variety of disorders often designated "idiopathic inflammatory myopathies". Although they are rather rare compared to other rheumatic diseases, they often cause severe disability and not infrequently increased mortality. The additional involvement of important internal organs such as the heart and lungs, is not uncommon. Thus, there is a great need for a better understanding of the etiopathogenesis of myositis, which may lead to improved treatment and care for these patients. Major advances regarding research and medical treatment have been made during recent years. Of particular importance is the discovery of the Myositis specific autoantibodies, linking immunological and pathological profiles to distinct clinical disease entities. A wide range of aspects of myopathies is covered in the book presented by highly qualified authors, all internationally known for their expertice on inflammatory muscle diseases. The book covers diagnostic, pathological, immunological and therapeutic aspects of myositis.

\title{
How to reference
}

In order to correctly reference this scholarly work, feel free to copy and paste the following:

Satoshi Nakano and Hirofumi Kusaka (2011). Myouclear Breakdown in Sporadic Inclusion Body Myositis, Idiopathic Inflammatory Myopathies - Recent Developments, Prof. Jan Tore Gran (Ed.), ISBN: 978-953-307694-2, InTech, Available from: http://www.intechopen.com/books/idiopathic-inflammatory-myopathies-recentdevelopments/myouclear-breakdown-in-sporadic-inclusion-body-myositis

\section{INTECH}

open science | open minds

\author{
InTech Europe \\ University Campus STeP Ri \\ Slavka Krautzeka 83/A \\ 51000 Rijeka, Croatia \\ Phone: +385 (51) 770447 \\ Fax: +385 (51) 686166 \\ www.intechopen.com
}

\author{
InTech China \\ Unit 405, Office Block, Hotel Equatorial Shanghai \\ No.65, Yan An Road (West), Shanghai, 200040, China \\ 中国上海市延安西路65号上海国际贵都大饭店办公楼 405 单元 \\ Phone: +86-21-62489820 \\ Fax: +86-21-62489821
}


(C) 2011 The Author(s). Licensee IntechOpen. This chapter is distributed under the terms of the Creative Commons Attribution-NonCommercialShareAlike-3.0 License, which permits use, distribution and reproduction for non-commercial purposes, provided the original is properly cited and derivative works building on this content are distributed under the same license. 